Nat. Hazards Earth Syst. Sci. Discuss., doi:10.5194/nhess-2016-379, 2017

Manuscript under review for journal Nat. Hazards Earth Syst. Sci.

Published: 2 January 2017

(c) Author(s) 2017. CC-BY 3.0 License.

\title{
Stochastic consideration of relationship between occurrences of earthquake and fluctuations in the radio wave propagation
}

\author{
Kuniyuki Motojima ${ }^{1}$, Kousuke Tanigawa ${ }^{1}$, and Nozomi Haga ${ }^{1}$ \\ ${ }^{1}$ Gunma University, 1-5-1, Tenjin-cho, Kiryu, Gumna 376-8515, Japan \\ Correspondence to: K. Motojima (motojima@gunma-u.ac.jp)
}

\begin{abstract}
Research of the geophysical electromagnetic phenomena with seismic activity is important for hazard-resistant strategy. Many papers which indicate the existence of geophysical electromagnetic phenomena associated with earthquakes are reported frequently. Anomalous propagation in the radio waves is sometimes related with earthquakes. In previous paper, authors proposed a new concept to estimate the relation between earthquakes and anomalous line-of-sight propagation in VHF band by statistical approach. Event probability of the anomalous line-of-sight propagation increased just a few days prior to earthquakes. In this paper, we investigated a new relationship between anomalous fluctuations in the radio waves, which propagated from line-of-sight region, and occurrences of earthquake by using statistical analysis. Monitoring the strength of radio waves and detecting the anomalous fluctuations by using a new original method, we can obtain the high probability which indicates strong relation between the anomalous propagation and occurrences of earthquake. After the stochastic consideration, we can find out the anomalous fluctuations, which appear one day prior to earthquakes near the wave propagation path.
\end{abstract}

\section{Introduction}

There exist probably some relations between earthquakes and electromagnetic phenomena in a global scale. Research of the relationship between both is very important for a country with frequent earthquakes, likes Japan. There are many reports about geophysical electromagnetic phenomena associated with earthquakes. Geophysical electromagnetic phenomena can be observable by using electromagnetic wave propagation. Almost reports on the geophysical electromagnetic phenomena are classified into two groups, direct observations (Gokhberg et al., 1982; Smith et al., 1990; Hayakawa et al. 1996) or indirect observations (Fujiwara et al., 2004; Hayakawa et al., 2010).

In indirect observations, radio wave propagation is monitored for investigating precursor of earthquakes. The target radio waves are almost in VLF and VHF bands. Anomalous perturbation at the bottom of ionosphere can be monitored by measuring the VLF radio waves propagation. An anomaly in ionosphere appears a few weeks prior to earthquake associated with it (Muto et al., 2009; Chakrabarti et al., 2010). Especially, some anomalies in signal amplitude and phase around sunrise and sunset times appeared a few days prior to the Kobe Japan earthquake, which occurred on 17th January 1995 (Molchanov and Hayakawa, 2007). 
Nat. Hazards Earth Syst. Sci. Discuss., doi:10.5194/nhess-2016-379, 2017

Manuscript under review for journal Nat. Hazards Earth Syst. Sci.

Published: 2 January 2017

(c) Author(s) 2017. CC-BY 3.0 License.

The other hand, there are many papers which report anomalous propagation in the VHF band waves from over-horizon broadcasting stations (Yonaiguchi et al., 2007). Yasuda et al. (Yasuda et al., 2009) reported that the anomalous propagation associated with earthquake occurs in the troposphere, and the anomaly affects the propagation path more $100 \mathrm{~km}$ or so away.

The purpose of our research is to find out any relation between occurrences of earthquake and anomalous line-of-sight propagation in the VHF band. We have been observed broadcasting radio waves from line-of-sight region for several years. In the previous paper (Motojima and Haga, 2014), we reported that there exists the relation of the two phenomena by using the statistical analysis, in which we proposed an original estimation method of probability. As the results of stochastic analysis, earthquakes associated with anomalous propagation were characterized by magnitude $M \geq 4.5$ near the propagation path.

In this paper we propose a new detection procedure of anomalous propagation associated earthquakes. In the new method, the fluctuations are derived from the strength of radio wave by using wavelet analysis method, and a new detection method is applied to the fluctuations. As the result of new method, we can get the high probability, which indicates strong relation between earthquakes and anomalous propagation.

\section{Anomalous line-of-sight propagation in the radio waves}

The purpose of this paper is to discover any relationship between anomalous fluctuations in the line-of-sight radio propagation and occurrences of earthquake. We set up an observatory of radio waves at Kiryu Japan $\left(36^{\circ} 25^{\prime} 26^{\prime \prime} N, 139^{\circ} 20^{\prime} 58^{\prime \prime} E\right)$, which is located about $90 \mathrm{~km}$ north from Tokyo. The system structure and features is described in previous paper (Motojima and Haga, 2014). The radio wave observatory can provide the data of monitoring wave strength. Some dozens of waves in VHF and UHF bands can be monitored by our observatory. In this paper some representative radio waves are analyzed and discussed in detail. The transmitter stations, path lengths from transmitting station to receiving station, names of broadcast station and frequency are listed as Table 1. Map position of the observatory, radio transmitter stations and wave propagation paths are described in Fig. 1. Black diamond is the observatory, sold black circles are the transmitting stations. Dashed lines show the wave propagation paths.

In most anomalies the fluctuations are occurred simultaneously in the multiple waves. Figure 2 shows an example of synchronism detection of anomalous fluctuation in the line-of-sight radio wave propagation. Figure 2 is the observational result on 3rd March 2015 in the multidirectional broadcasting waves, which were incoming from three transmitter stations - Tokyo Tower, Miyama and Hiranohara stations - as shown in Fig. 1. Each black solid line indicates the received signal strength. Each green line indicates mean value $(m)$. Two blue lines mean an upper limit of ordinary propagation $(m+3 \sigma)$ and a lower limit of it $(m-3 \sigma)$, they were statistically derived from the long term observational data, from 2012 to 2015.

In each broadcasting wave, simultaneous anomalous fluctuation occurred at the same time: from 6 p.m. to 8 p.m. on 3rd May 2015. The wave from Miyama station showed most obvious anomaly, which is indicated in red dashed circles. First anomaly appeared in the predawn hours, then simultaneous anomaly occurred after sunset and was lasting until 11 p.m. An earthquake happened subsequent to these anomalous fluctuations in a few hours later. It occurred at 23:30 LT on 3rd May 2015, 4.7 
Nat. Hazards Earth Syst. Sci. Discuss., doi:10.5194/nhess-2016-379, 2017

Manuscript under review for journal Nat. Hazards Earth Syst. Sci.

Published: 2 January 2017

(c) Author(s) 2017. CC-BY 3.0 License.

(c) (i)
Natural Hazards

and Earth System

Sciences

Discussions

magnitude earthquake, centered in northern Kanto Plain $\left(36^{\circ} 25^{\prime} 26^{\prime \prime} N, 139^{\circ} 20^{\prime} 58^{\prime \prime} E\right)$. These anomalous fluctuations may be the precursor of the earthquake.

\section{Wavelet analysis of received radio waves}

In the previous paper, we adopted a criteria based on signal strength level as decision for detecting anomalous propagation.

5 Received signal strength beyond $(m+3 \sigma)$ or $(m-3 \sigma)$ was regarded as anomalous data, they are the detection thresholds. However, propagated radio signal is influenced by climatic phenomena. Climatic phenomena make frequently anomalous level of received wave strength associated without earthquake. To avoid the influence of level variation, we adopt the wavelet analysis of temporal variation in received radio waves. For the purpose, operating procedure of data, that is received radio wave strength, noted as follows.

1. Calculation of mean $m$ and standard deviation $\sigma$

Radio wave propagation is affected by daily variation, because sunlight promotes atmospheric convection. The atmospheric convection decreases in the difference of atmospheric refractivity between upper and lower atmosphere. Under normal condition, therefore, signal strength in daytime is slightly weak and stable, in night time signal strength is slightly strong and unstable. In order to take away that daily variation, received data is normalized separately each time slot of a day. In our procedure, a day is divided into 288 time slots of five minutes, $0: 00 \sim 0: 05,0: 05 \sim 0: 10, \cdots, 23: 55 \sim$ $24: 00$ and the data is normalized separately each time slot. Mean value $m$ and standard deviation $\sigma$ of each time slot are derived through the whole observation period, about three years. Therefore, 288 mean values $m_{i}$ and 288 standard deviations $\sigma_{i}$ are calculated for $i=1,2, \cdots, 288$.

2. Normalized data of received wave strength

In order to detect anomalous fluctuation, normalized data is calculated from the mean of each time slot $m_{i}$ in units of the standard deviation of each time slot $\sigma_{i}$, as following equation.

$$
\begin{array}{r}
\text { Normalized data } x=\frac{(\text { Received signal data })-\left(\text { Mean value } m_{i} \text { of corresponding time slot } i\right)}{\text { Standard deviation } \sigma_{i} \text { of the corresponding time slot } i} \\
(i=1,2, \cdots, 288)
\end{array}
$$

Equation (1) provides the corrected deviation free from the influence of daily variation.

3. Wavelet transformation 
Nat. Hazards Earth Syst. Sci. Discuss., doi:10.5194/nhess-2016-379, 2017

Manuscript under review for journal Nat. Hazards Earth Syst. Sci.

Published: 2 January 2017

(c) Author(s) 2017. CC-BY 3.0 License.

Wavelet transform of the normalized data $x$ is taken as the continuous wavelet transform (CWT). Wavelet coefficients $W(b, a)$ is given as following.

$W(b, a)=\frac{1}{\sqrt{a}} \int_{-\infty}^{+\infty} \psi^{*}\left(\frac{t-b}{a}\right) x(t) d t$

where $a$ is scale and $b$ is translational value, $x(t)$ is the normalized data. The $\psi^{*}$ is the complex conjugate function of

$$
\psi(t)=\frac{1}{\sqrt[4]{\pi}} \exp (j \omega t) \exp \left(-\frac{t^{2}}{2}\right), \quad \omega=\pi \sqrt{\frac{2}{\ln (2)}}
$$

The wavelet coefficients are complex number because the Morlet wavelet is complex number. Then, we take absolute value of the wavelet coefficients.

\section{Extraction of larger wavelet coefficients}

Larger data in the top of $0.08 \%$ are extracted from the whole data of absolute wavelet coefficients. When a sequential larger coefficients appear in a few hours, we recognized the data as occurrence of anomalous fluctuation.

Figure 3 is an example of wavelet coefficients. Horizontal dashed line means the threshold level, which was determined by the number of larger data. The wavelet coefficients exceeded the threshold level three times from 14:42 to 21:16 LT on 12th Nov. 2012. Duration time of the exceeded wavelet coefficients was 6 hours and 34 minutes. We regarded it as occurrence of anomalous fluctuation.

\section{Stochastic consideration between anomalous fluctuation and occurrence of earthquake}

We defined the successive occurrence of anomalous fluctuation and earthquake within a short period of time as "occurrence of anomalous fluctuation associated with earthquake." However, even if there were no relation between the anomalous fluctuation and earthquake, both just happened to occur during a short term. Therefore, an unrelated probability $P_{\text {unrel }}$ of the successive occurrence of both phenomena has to be estimated and to be compared with probability of observational occurrence $P_{o b s}$.

In order to derive the formula for the $P_{\text {unrel }}$, let's consider that only one anomaly and only one earthquake occurs under no relation during the entire observing period, $T_{\text {all }}$. At first, we derive a probability of NOT successive occurrence of both in defined time period $t_{p e r},\left.\bar{P}_{\text {unrel }}\left(t_{p e r}\right)\right|_{N e q=1}$. To simplify, time of occurrence of anomaly is fixed. The $\left.\bar{P}_{\text {unrel }}\left(t_{p e r}\right)\right|_{\text {Neq=1 }}$ is the probability of occurrence of earthquake at complementary time period. Therefore, the $\left.\bar{P}_{\text {unrel }}\left(t_{p e r}\right)\right|_{\text {Neq=1 }}$ can be obtained as follows.

$\left.\bar{P}_{\text {unrel }}\left(t_{\text {per }}\right)\right|_{\text {Neq=1 }}=\frac{T_{\text {all }}-\left|t_{\text {per }}\right|}{T_{\text {all }}}$ 
Nat. Hazards Earth Syst. Sci. Discuss., doi:10.5194/nhess-2016-379, 2017

Manuscript under review for journal Nat. Hazards Earth Syst. Sci.

Published: 2 January 2017

(c) Author(s) 2017. CC-BY 3.0 License.

where $t_{p e r}$ is the defined length of time period associated anomalous fluctuation with earthquake, $T_{\text {all }}$ is the amount of observing time $\left(T_{\text {all }}=1095\right.$ days $)$.

Next, let's consider two earthquakes occur out of defined time period, $t_{p e r}$. It's probability is equal to the square of $\left.\bar{P}_{\text {unrel }}\left(t_{p e r}\right)\right|_{N e q=1}$. Because it is the conditional probability that first earthquake occurs out of $t_{p e r}$ and second earthquake 5 occurs out of $t_{\text {per }}$ too.

By the same token, when the number of earthquakes which occur out of $t_{p e r}$ is $N_{e q}$, the probability can be obtained as next equation.

$\left.\bar{P}_{\text {unrel }}\left(t_{p e r}\right)\right|_{\text {Neq }}=\left(\frac{T_{\text {all }}-\left|t_{\text {per }}\right|}{T_{\text {all }}}\right)^{N_{e q}}$

where the $N_{e q}$ is the number of occurrence of earthquake during the whole observation period $T_{a l l}$.

The event which the anomaly and earthquakes just happen to occur in a defined time period $t_{p e r}$ is complementary event of $\left.\bar{P}_{\text {unrel }}\left(t_{\text {per }}\right)\right|_{\text {Neq }}$. Therefore, the unrelated probability $P_{\text {unrel }}\left(t_{\text {per }}\right)$ of the sequential occurrence of the anomaly and earthquakes can be obtained as follows (Motojima and Haga, 2014).

$P_{\text {unrel }}\left(t_{\text {per }}\right)=1-\left(\frac{T_{\text {all }}-\left|t_{\text {per }}\right|}{T_{\text {all }}}\right)^{N_{\text {eq }}}$

The probability of observational occurrence $P_{o b s}$ can be obtained from the results of observation, as follows.

$P_{o b s}\left(t_{p e r}\right)=\frac{N_{o b s}\left(t_{p e r}\right)}{N_{\text {anom }}}$

where the $N_{o b s}\left(t_{p e r}\right)$ is the number of occurrence of anomalous fluctuation associated with earthquake in the length of time period $t_{\text {per }}$. The $N_{\text {anom }}$ is the number of occurrence of anomalous fluctuation during the whole observation period $T_{a l l}$.

The number of occurrence of anomalous fluctuation associated with earthquakes $N_{o b s}\left(t_{p e r}\right)$ depends on the length of defined time period $t_{p e r}$, because the longer defined time period $t_{\text {per }}$ makes the more anomalous fluctuation identified as "occurrence of anomalous fluctuation associated with earthquake." Besides, the unrelated probability $P_{\text {unrel }}\left(t_{p e r}\right)$ also depends on the $t_{p e r}$. The longer $t_{p e r}$ makes the more unrelated probability $P_{\text {unrel }}\left(t_{p e r}\right)$ too. Therefore, we proposed an original concept of the probability gain $P G$ for estimating the relationship between the anomalous fluctuation and earthquake in the previous paper (Motojima and Haga, 2014). The probability gain $P G$ is the ratio of the observational probability $P_{o b s}$ to the unrelated probability $P_{\text {unrel }}$, it can be obtained as follows.

$P G\left(t_{\text {per }}\right)=\frac{P_{\text {obs }}\left(t_{\text {per }}\right)}{P_{\text {unrel }}\left(t_{\text {per }}\right)}$

If the $P G$ closes to one, comparable probability of both the observational probability $P_{o b s}$ and the unrelated probability $P_{\text {unrel }}$, it means that there may be no relation between the anomalous fluctuation and earthquake. 
Nat. Hazards Earth Syst. Sci. Discuss., doi:10.5194/nhess-2016-379, 2017

Manuscript under review for journal Nat. Hazards Earth Syst. Sci.

Published: 2 January 2017

(c) Author(s) 2017. CC-BY 3.0 License.

\section{Result and discussion}

The wavelet coefficients vary depending on the scale $a$ of mother wavelet. Moreover, the $N_{e q}$, which is the number of earthquakes during the whole observation period $T_{\text {all }}$, also varies depending on the size of earthquakes, depth of hypocenter and epicenter area. Therefore, we searched the best parameters with respect to the probability gain $P G$. Searching parameters are the scale $a$ of Morlet wavelet, the seismic magnitude $M$, depth of hypocenter $D$, distance between the wave path and epicenter location $L$. Scope of each parameter is listed in Table 2. Target broadcasting wave was NHK FM Tokyo from Sky Tree transmitting station, $82.5 \mathrm{MHz}$. We calculated the probability gain $P G$ in all combinations of parameters, $a, M, D$ and $L$, which combination number is 567 . As the result of calculation in all combinations, the largest number of the probability gain $P G$ is $P G=7.213$ for $a=9.775, M \geq 4.5, D \leq 50 \mathrm{~km}$ and $L \leq 100 \mathrm{~km}$. It indicates that the occurrence probability of earthquake under appearance of anomalous fluctuation rise up to 7.213 times higher than no anomaly observed.

The probability gain $P G\left(t_{p e r}\right)$ also varies depending on the defined length of time period associated anomalous fluctuation with earthquake $t_{p e r}$, because both the observational probability $P_{o b s}$ and the unrelated probability $P_{\text {unrel }}$ change depending on the $t_{p e r}$. And so, we also calculated the probability gain $P G\left(t_{p e r}\right)$ with respect to $t_{p e r}=-7 \sim+7($ days $)$. The sign of $t_{p e r}$ means occurrence of anomaly before or after earthquake. Minus is anomaly prior to earthquake, plus is the opposite. The variation in the probability gain $P G\left(t_{p e r}\right)$ with respect to $t_{\text {per }}$ shows in Fig. 4 for NHK FM Tokyo wave. In Fig. 4 the probability gain $P G\left(t_{p e r}\right)$ has a peak at $t_{p e r}=-1($ days $)$. It indicates that anomalous fluctuation appears a day before earthquake frequently. In other minus $t_{p e r}$ the probability gain $P G\left(t_{p e r}\right)$ shows about three or more. On the other hand the $P G\left(t_{p e r}\right)$ becomes smaller after the earthquake, it is around one. Figure 4 implies that anomalous fluctuations occur before earthquakes frequently.

We analyzed other broadcasting waves coming from other stations. The parameters $a, M, D$ and $L$ are same as the analysis for NHK FM Tokyo in Fig. 4. Table 3 shows the probability gain $P G$ for monitoring waves at our observatory. Incoming waves from Tokyo tower, Sky tree, Miyama and Hiranohara stations indicate high probability gain $P G$, which are $P G=3.290 \sim 7.213$. This result implies that the anomalous fluctuations appear on plural waves coming from multidirectional stations. Anomalous fluctuations occur in the incoming VHF waves from line-of-sight region.

We think that the high probability gain $P G$ is not enough for that perspective. Therefore we estimate a hit rate and an alarm rate. The hit rate means a reliability of detection for anomalous fluctuations associated with earthquakes. The alarm rate means predictability of earthquakes by using anomalous fluctuations. They can be obtained as following.

Hit rate $=\frac{\text { Number of anomalous fluctuations associated with earthquakes }}{\text { Number of anomalous fluctuations }}$

Alarm rate $=\frac{\text { Number of earthquakes associated with anomalous fluctuations }}{\text { Number of earthquakes }}$ 
Nat. Hazards Earth Syst. Sci. Discuss., doi:10.5194/nhess-2016-379, 2017

Manuscript under review for journal Nat. Hazards Earth Syst. Sci.

Published: 2 January 2017

(c) Author(s) 2017. CC-BY 3.0 License.

(c) (i)

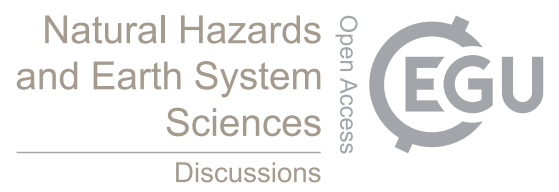

Both rates are also shown for each wave in Table 3. The result of both rates indicate that our method is not enough to clear the precursor of earthquake. However, high probability gain $P G$ implies any existence of the relationship between the anomalous fluctuations and earthquakes strongly.

\section{Summary}

5 In this paper, the relationship between anomalous line-of-sight propagation and occurrences of earthquake is investigated by monitoring the fluctuations in the received wave strength. In order to make more clearly the relationship of both, we applied the new method, which is the wavelet analysis of received wave strength. Anomalous phenomenon exists in the shape of anomalous fluctuation of the received wave strength. Using the wavelet analysis, we can find out the relationship of both. Then, we adopted the original evaluation method, which is calculation of the probability gain $P G$. The maximum probability gain $P G$ is 7.213 , which appears in broadcast wave of NHK FM Tokyo, frequency $f=82.5 M H z$, from Sky tree transmitting station. Moreover, other broadcasting waves incoming from line-of-sight region have anomalous fluctuations associated with earthquakes similarly as NHK FM Tokyo broadcasting wave. This result suggests that the existence of relationship between anomalous fluctuations in radio waves and occurrences of earthquake.

We investigated only a few wavelet analysis methods. Many analysis methods have not been tried yet. These are in future works.

Acknowledgements. This work was partially supported by JSPS KAKENHI Grant Number 26420382. Earthquake Information of Japan Meteorological Agency was referred for our statistical investigation. 
Nat. Hazards Earth Syst. Sci. Discuss., doi:10.5194/nhess-2016-379, 2017

Manuscript under review for journal Nat. Hazards Earth Syst. Sci.

Published: 2 January 2017

(c) Author(s) 2017. CC-BY 3.0 License.

(c) (i)
Natural Hazards

and Earth System

Sciences

Discussions

\section{References}

Chakrabarti, S. K., Sasmal, S., and Chakrabarti S.: Ionospheric anomaly due to seismic activities - Part 2: Evidence from D-layer preparation and disappearance times, Nat., Hazards Earth Syst. Sci., 10, 1751-1757, doi:10.5194/nhess-10-1751-2010, 2010.

Fujiwara, H., Kamogara, M., Ikeda, M., Liu, J. Y., Sakata, H., Chen, Y. I., Ofuruton, H., Muramatsu, S., Chuo, Y. J., and Ohtsuki, Y. H.: Atmospheric anomalies observed during earthquake occurrences, Geophys. Res. Lett., 31, L17110, doi:10.1029/2004GL019865, 2004.

Gokhberg, M. B., Morgounov, V. A., Yoshino, T., and Tomizawa, I.: Experimental measurement of electromagnetic emissions possibly related to earthquakes in Japan, J. Geophys. Res., 87, 7824-7828, 1982.

Hayakawa, M., Kawate, R., Molchanov, O. A., and Yumoto, K.: Results of ultra-low-frequency magnetic field measurements during the Guam earthquake of 8 August 1993, Geophys. Res. Lett., 23, 241-244, doi:10.1029/95GL02863, 1996.

Hayakawa, M., Kasahara, Y., Nakamura, T., Muto, F., Horie, T., Maekawa, S., Hobara, Y., Rozhnoi, A. A., Solovieva, M., and Molchanov, O., A.,: A Statistical study on the correlation between lower ionospheric perturbations as soon by subionospheric VLF/LF propagation and earthquakes, J. Geophys. Res., 115, A09305, doi:10.1029/2009JA015143, 2010.

Molchanov, O. A., and Hayakawa, M.: Subionospheric VLF signal perturbations possibly related to earthquakes, J. Geophys. Res., 103, 17489-17504, doi:10.1029/98JA00999, 1998.

Motojima K., and Haga N.: Stochastic relation between anomalous propagation in the line-of-sight VHF radio band and occurrences of earthquakes, Nat., Hazards Earth Syst. Sci., 14, 2119-2124, doi:10.5194/nhess-14-2119-2014, 2014.

Muto, F., Kasahara, Y., Hobara, Y., Hayakawa, M., Rozhnoi, A., Solovieva, M., and Molchanov, O. A.,: Further study on the role of atmospheric gravity waves on the seismo-ionospheric perturbations as detected by subionospheric VLF/LF propagation, Nat., Hazards Earth Syst. Sci., 9, 1111-1118, 2009.

Smith, A. C. F., Bernardi, A., McGill, P. R., Ladd, M. E., Helliwell, R. A., and Villard, O. G. Jr.: Low-frequency magnetic field measurements near the epicenter of the Ms 7.1 Loma Prieta earthquake, Geophys. Res. Lett., 17, 1465-1468, doi:10.1029/GL017i009p01465, 1990.

Yasuda, Y., Ida, Y., Goto, T., and Hayakawa, M.: Interferometric direction finding of over-horizon VHF transmitter signals and natural VHF radio emissions possibly associated with earthquakes, Radio Sci., 44, RS2009, doi:10.1029/2008RS003884, 2009.

Yonaiguchi, N., Ida, Y. and Hayakawa, M.: On the statistical correlation of over-horizon VHF signals with meteorological radio ducting and seismicity, J. Atmos. Solar-terr. Phys., 69, 661-674, doi:10.1016/j.jastp.2007.01.007, 2007. 
Nat. Hazards Earth Syst. Sci. Discuss., doi:10.5194/nhess-2016-379, 2017

Manuscript under review for journal Nat. Hazards Earth Syst. Sci.

Published: 2 January 2017

(c) Author(s) 2017. CC-BY 3.0 License.

(c) (i)

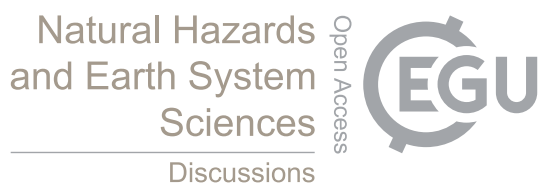

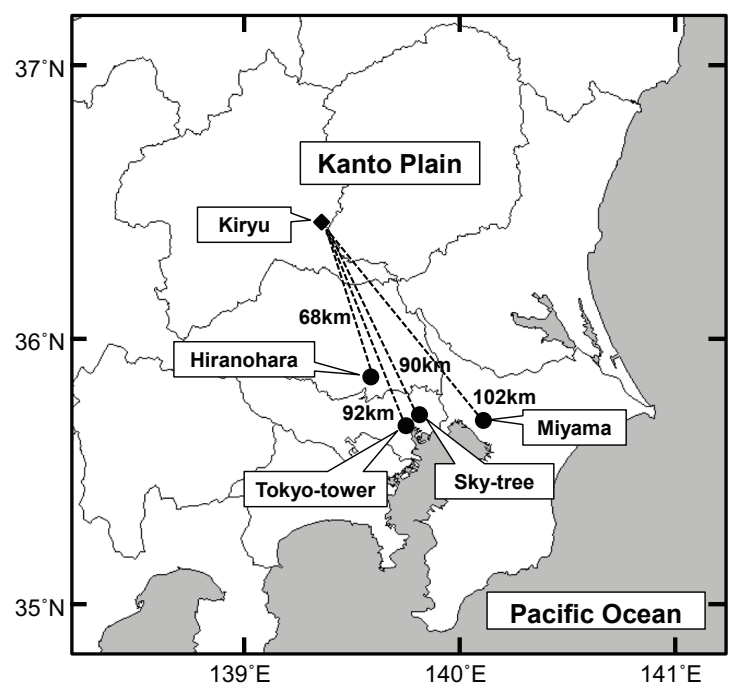

Figure 1. Map of observatory, transmitter stations and wave propagation paths. Black diamond is the observatory, solid black circles are the transmitter stations. Dashed lines show the wave propagation paths. 
Nat. Hazards Earth Syst. Sci. Discuss., doi:10.5194/nhess-2016-379, 2017

Manuscript under review for journal Nat. Hazards Earth Syst. Sci.

Published: 2 January 2017

(c) Author(s) 2017. CC-BY 3.0 License.

(c) (1)

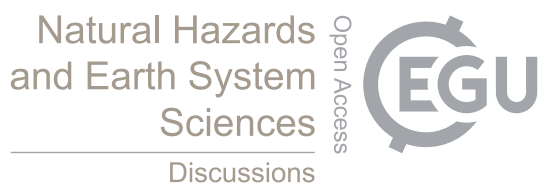

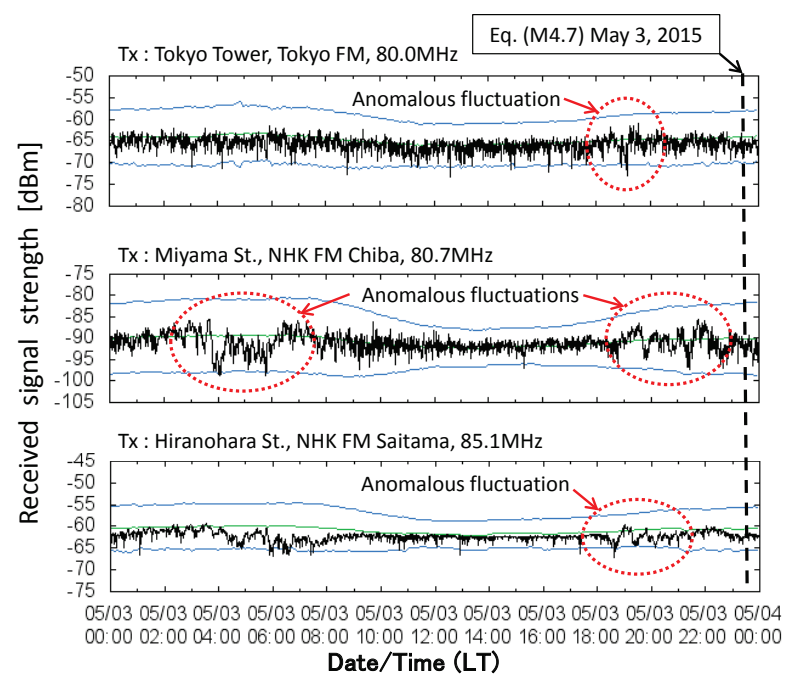

Figure 2. An example of synchronism detection of anomalous fluctuations in the line-of-sight stations on 3rd May 2015. Each green line indicates mean value $(m)$, two blue lines mean an upper limit of ordinary propagation $(m+3 \sigma)$ and a lower limit of it $(m-3 \sigma)$. Earthquake occurred at 23:30 LT on 3rd May 2015, seismic magnitude 4.7, epicenter $\left(36^{\circ} 25^{\prime} 26^{\prime \prime} N, 139^{\circ} 20^{\prime} 58^{\prime} E\right)$ in northern Kanto Plain. 
Nat. Hazards Earth Syst. Sci. Discuss., doi:10.5194/nhess-2016-379, 2017

Manuscript under review for journal Nat. Hazards Earth Syst. Sci.

Published: 2 January 2017

(c) Author(s) 2017. CC-BY 3.0 License.

(c) (1)

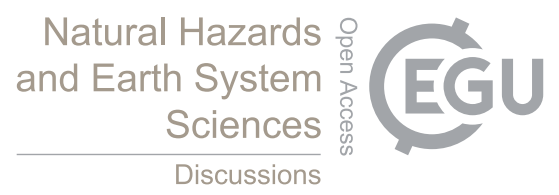

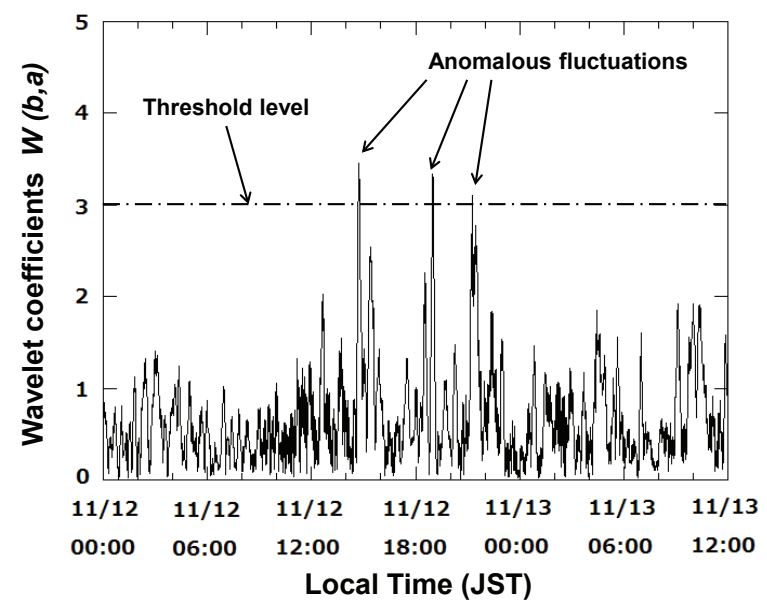

Figure 3. An example of anomalous fluctuation in wavelet coefficients $W(b, a)$ from 12th to 13th Nov. 2012. Scale of mother wavelet $a=9.775$, threshold level 3.0. 
Nat. Hazards Earth Syst. Sci. Discuss., doi:10.5194/nhess-2016-379, 2017

Manuscript under review for journal Nat. Hazards Earth Syst. Sci.

Published: 2 January 2017

(c) Author(s) 2017. CC-BY 3.0 License.

(c) (1)

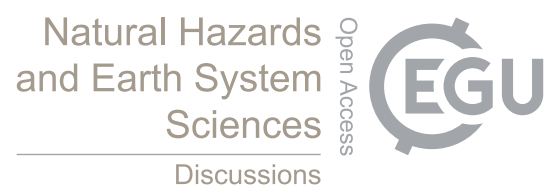

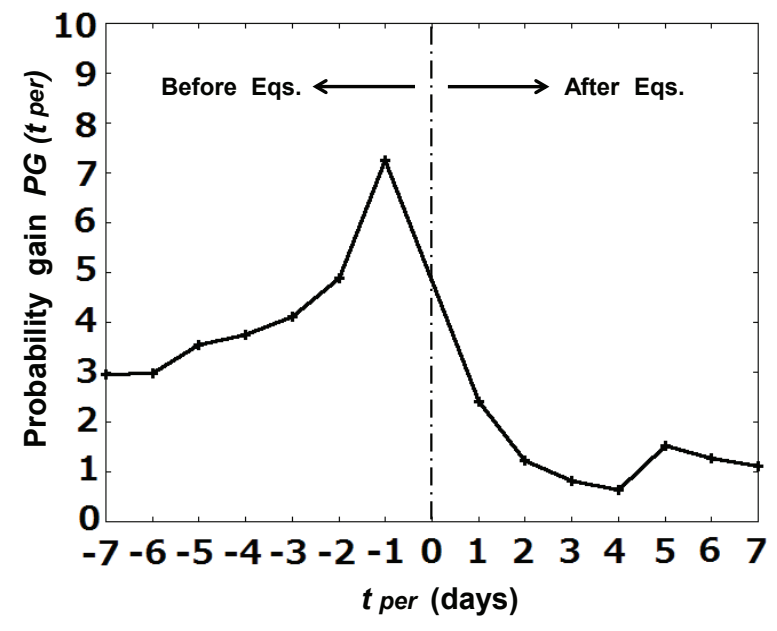

Figure 4. The probability gain $P G\left(t_{p e r}\right)$ for NHK FM Tokyo wave. Scale of mother wavelet $a=9.775$, seismic magnitude $M \geq 4.5$, depth of hypocenter $D \leq 50 \mathrm{~km}$, distance between the wave path and epicenter location $L \leq 100 \mathrm{~km}$. 
Nat. Hazards Earth Syst. Sci. Discuss., doi:10.5194/nhess-2016-379, 2017

Manuscript under review for journal Nat. Hazards Earth Syst. Sci.

Published: 2 January 2017

(c) Author(s) 2017. CC-BY 3.0 License.

(c) (i)

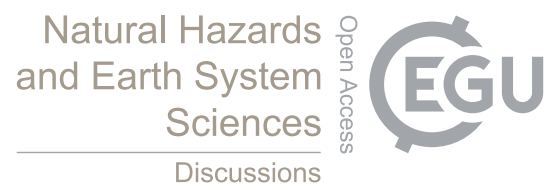

Table 1. The transmitter stations, path lengths from Tx to Rx, names of broadcast station and transmit frequency.

\begin{tabular}{cccc}
$\begin{array}{c}\text { Transmitter } \\
\text { station }\end{array}$ & $\begin{array}{c}\text { Path length } \\
\text { from Tx. to Rx. }\end{array}$ & Name of broadcast station & $\begin{array}{c}\text { Transmit } \\
\text { frequency }\end{array}$ \\
\hline $\begin{array}{c}\text { Tokyo tower } \\
\text { (Tokyo) }\end{array}$ & $92 \mathrm{~km}$ & FM Tokyo & $80.0 \mathrm{MHz}$ \\
& & The Open Univ. of Japan & $77.1 \mathrm{MHz}$ \\
Sky tree & $90 \mathrm{~km}$ & NHK FM Tokyo & $82.5 \mathrm{MHz}$ \\
(Tokyo) & & Jwave & $81.3 \mathrm{MHz}$ \\
\hline Miyama St. & $102 \mathrm{~km}$ & NHK FM Chiba & $80.7 \mathrm{MHz}$ \\
(Chiba Pref.) & & Bay FM & $78.0 \mathrm{MHz}$ \\
\hline Hiranohara St. & $68 \mathrm{~km}$ & NHK FM Saitama & $85.1 \mathrm{MHz}$ \\
(Saitama Pref.) & & TV Saitama & $587 \mathrm{MHz}$ \\
\hline
\end{tabular}


Nat. Hazards Earth Syst. Sci. Discuss., doi:10.5194/nhess-2016-379, 2017

Manuscript under review for journal Nat. Hazards Earth Syst. Sci.

Published: 2 January 2017

(c) Author(s) 2017. CC-BY 3.0 License.

(c) (1)

Table 2. Searching parameters with respect to the probability gain $P G$, NHK FM Tokyo, $f=82.5 \mathrm{MHz}$.

\begin{tabular}{ccc}
\hline Parameter & Scope of parameters & Number of kinds \\
\hline Scale of mother wavelet $a$ & $4.887 \sim 156.4$ & 21 \\
\hline Seismic magnitude $M$ & $M \geq 4.5, \quad M \geq 5.0, M \geq 5.5$ & 3 \\
\hline Depth of hypocenter $D$ & $D \leq 50 \mathrm{~km}, D \leq 75 \mathrm{~km}, D \leq 100 \mathrm{~km}$ & 3 \\
\hline $\begin{array}{c}\text { Distance between wave path } \\
\text { path and epicenter location } L\end{array}$ & $L \leq 50 \mathrm{~km}, L \leq 100 \mathrm{~km}, L \leq 150 \mathrm{~km}$ & 3 \\
\hline
\end{tabular}


Nat. Hazards Earth Syst. Sci. Discuss., doi:10.5194/nhess-2016-379, 2017

Manuscript under review for journal Nat. Hazards Earth Syst. Sci.

Published: 2 January 2017

(c) Author(s) 2017. CC-BY 3.0 License.

(c) (1)

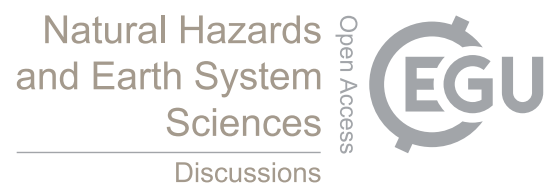

Table 3. The probability gain $P G$, the number of earthquake $N_{e q .}$, the number of anomalous fluctuation $N_{\text {anom. }}$, Hit rate and Alarm rate ( $t_{\text {per }}=-1($ days $\left.), a=9.775, M \leq 4.5, D \leq 50 \mathrm{~km}, L \leq 100 \mathrm{~km}\right)$.

\begin{tabular}{ccccccc}
\hline Broadcast station name & $\begin{array}{c}\text { Transmitting station } \\
\text { (Radion path length) }\end{array}$ & $N_{\text {eq. }}$ & $N_{\text {anom. }}$ & PG & Hit rate & Alarm rate \\
\hline NHK FM Tokyo & $\begin{array}{c}\text { Sky tree } \\
(92 \mathrm{~km})\end{array}$ & 27 & 17 & 7.213 & 0.176 & 0.111 \\
& $\begin{array}{c}\text { Tokyo tower } \\
(90 \mathrm{~km})\end{array}$ & 24 & 28 & 3.290 & 0.0714 & 0.083 \\
\hline FM Tokyo & Hiranohara St. & 22 & 23 & 4.372 & 0.087 & 0.091 \\
& $(68 \mathrm{~km})$ & & & & & 0.081 \\
\hline NHK FM Saitama & Miyama St. & 37 & 29 & 4.154 & 0.138 & \\
\hline NHK FM Chiba & $(68 \mathrm{~km})$ & & & & & \\
& & & & & & \\
\hline
\end{tabular}

